\title{
ARE PROGNOSTIC INDICATORS FOR POOR OUTCOME DIFFERENT FOR ACUTE AND CHRONIC LOW BACK PAIN CONSULTERS IN PRIMARY CARE?
}

\author{
Margreth Grotle, PT, PhD, \\ FORMI (Communication Unit for Musculoskeletal Disorders), Division for Neuroscience and \\ Musculoskeletal Medicine, Oslo University Hospital, Ullevaal, Oslo; National Resource Centre for \\ Rehabilitation in Rheumatology, Diakonhjemmet Hospital, Oslo \\ Nadine E. Foster [Prof], \\ Professor of Musculoskeletal Health in Primary care, Arthritis Research UK National Primary \\ Care Centre, Keele University, UK \\ Kate M. Dunn, PhD, and \\ Senior Lecturer in Epidemiology, Arthritis Research UK National Primary Care Centre, Keele \\ University, UK \\ Peter Croft [Prof] \\ Professor of Primary Care Epidemiology, Arthritis Research UK National Primary Care Centre, \\ Keele University, UK
}

\section{Abstract}

\begin{abstract}
Few studies have investigated whether prognostic indicators, which contribute to the transition from acute to chronic low back pain (LBP), are also those which contribute to continuing persistence of chronic LBP. We compared the contribution of physical, psychological and social indicators to predicting disability after one year between consulters with LBP of less than 3 months duration and more than 3 months duration. Data from two large prospective cohort studies of consecutive patients consulting with LBP in general practices were merged, providing complete data for 258 cases with acute/subacute LBP and 668 cases with chronic LBP at 12 months followup. There were significant differences between the two LBP groups in baseline characteristics and clinical course of disability, assessed by Roland Morris Disability Questionnaire, during the year of follow-up. Adjusted associations between potential prognostic indicators and disability at 12 months were carried out in the two LBP subgroups. The final multivariable regression models showed that being non-employed, having widespread pain, a high level of Chronic Pain Grade, and catastrophising were the strongest prognostic indicators for disability at 12 months in both LBP groups. Fear of pain was significantly associated with disability in chronic LBP. Importantly, beyond baseline disability, the effect size of the other prognostic indicators for poor outcome was rather low. These findings must continue to challenge researchers to identify useful early predictors of outcome in persons with disabling back pain, as screening and targeted treatment approaches are dependent upon prognostic indicators with clinical significance.
\end{abstract}

Corresponding Author: Dr Margreth Grotle, PhD.

We declare that there is no conflicts of interest. 


\section{Introduction}

Most back pain clinicians and researchers make a distinction between acute and chronic low back pain (LBP), an approach in line with clinical guidelines [1;44]. This distinction is reasonable when considering the different prognoses of these two LBP groups. Most studies confirm that, while the natural clinical course is good following an episode of acute LBP as measured by decreases in pain and disability over the first weeks for the majority of patients $[11 ; 26 ; 40 ; 42 ; 45]$, there are only minor changes in pain and disability in patients presenting with long-term or chronic LBP [11;47].

Despite a large body of research on prognostic indicators for poor outcome, few studies have investigated whether prognostic indicators are similar across different subgroups of the back pain population. One reason for the limited research might be that it seems inevitable that factors that cause acute pain to become chronic will also act as a barrier to recovery of chronic pain. This view is supported in a recent Australian study showing a large overlap in prognostic indicators for recovery in acute [18] and chronic LBP [4]. Similar findings have also been reported among first-time consulters in primary care with acute LBP and secondary care consulters with chronic LBP [16]. On the other hand, this does not mean that the risk factors for development of chronic pain will be identical to those which cause it to persist. In hypothetical terms, severity of trauma might be a significant influence on why an acute pain becomes chronic; a few months down the line, this may no longer be the case, and consequences of the pain (such as depression, poor sleep, job loss) may be more crucial influences on whether the chronic pain persists after the effects of the original injury have disappeared. Furthermore, one could argue that if prognostic indicators are similar across different LBP groups, it may not be necessary to distinguish between acute and chronic LBP in primary care, questioning clinical guidelines that continue to refer to acute and chronic LBP cases separately.

Another reason for few studies in this area might be that investigating prognostic indicators across subgroups requires a large sample size. According to several systematic reviews of prospective LBP studies exploring prognostic factors for poor outcome [7;19;22;24;28;32;33;37-39;41], most studies have small sample sizes and poor statistical power to explore such associations across subgroups. One way around this challenge is to merge data sets from different studies, on similar populations and which have used similar design and assessment methods. lore such associations across subgroups. One way around this challenge is to merge data sets from different studies, on similar populations and which have used similar design and assessment methods.

We merged two large cohorts of patients who had consulted in primary care because of nonspecific LBP. We used the biopsychosocial model as our theoretical construct and classified the different prognostic indicators into groups of physical, psychological and social variables. The aim of this study was to compare the contribution of physical, psychological and social indicators to predicting disability after one year between consulters with LBP of less than 3 months duration and more than 3 months duration.

\section{Methods}

\subsection{Design and setting}

Two large prospective cohort studies of consecutive patients consulting with LBP in general practices in the Keele General Practice (GP) Partnership in UK were merged. The analysis for this study is based on participants who consented and returned the baseline and 12 month follow-up questionnaire. The rationale for including the variables under study was two-fold; first; we included all the variables that the two data sets had in common, and second; we 
included variables that covered the three components of the biopsychosocial model. Ethical approval for the study was obtained from the North Staffordshire and Central Cheshire Research Ethics Committees and permission was given by each general practice.

\subsection{Patients and recruitment}

The first data set, the Backpain Research in North Staffordshire (BaRNS) Study, consisted of 935 participants, aged 30-59 years, recruited from five general practices in North Staffordshire during October 2001-October 2002. The second data set, the BeBack study, consisted of 1591 participants, aged 18-60 years, recruited from eight general practices in North Staffordshire and Central Cheshire from September 2004 to April 2006. These general practices cover a heterogeneous population, both socio-economically and geographically. Both cohort studies included patients consulting with non-specific LBP of varying duration and localisation (including pain radiating to lower extremity). Patients with red flag diagnoses (e.g. cauda equine syndrome, significant trauma, ankylosing spondylitis, cancers) were excluded. All participants received usual care from their general practitioner. Further details of the two data sets are available in previous publications $[10 ; 14]$.

\subsection{Merged variables}

The definition proposed by de Vet et al [8;11], which records the time since last pain-free month, was used to classify the current participants into acute/subacute LBP group with pain duration of less than 3 months and a chronic LBP group with pain duration of 3 months or more. The demographic, social, physical and two of the psychological variables were all recorded in a similar way in the two data sets. Age was categorised into four age groups; = $37,38-45,46-52$ and $=53$ years. Level of education was categorised into education up to the age of 16 and 16 years or over. Social class was dichotomised into higher (managerial/ professional and intermediate occupations, and self-employed) and lower (lower supervisory/technical, semi-routine and routine occupations) [29]. Work absence due to LBP was defined as those who were employed but currently off work due to LBP plus people who were unemployed and reported that this was due to LBP. Work dissatisfaction was defined as slight or severe dissatisfaction with their work (employed only).

The presence or absence of leg pain, distal leg pain (below knee) and upper body pain (shoulder, arm, neck or head) over the two last weeks was collected. Widespread pain was categorised according to the number of upper body pain sites (one, two, three or more) in addition to LBP. Pain intensity was measured using the mean of three 0-10 numerical rating scales for least and usual back pain over the previous two weeks, and current back pain intensity; a score of 5 or more was defined as high pain intensity. Bothersomeness was assessed by the single question of how bothersome the back pain had been the last two weeks [9]. Previous studies have found bothersomeness to be a valid measure of LBP severity [10]. The Chronic Pain Grade [46] classifies persons into one of five grades of chronic back pain, ranging from 0 (pain free) to IV (high disability, severely limiting), and was categorised into low (0-II: no or low disability) and high (III-IV: high disability). The severity variables -pain intensity, bothersomeness and Chronic Pain Grade -were dichotomised to simplify the interpretation of the associations, and in general the approach of dichotomising continuous or interval variables reflects the intention of this study to investigate effect estimates of odds and risk for a number of variables that are easily interpretable. Self-reported disability due to LBP was measured by the Roland and Morris Disability Questionnaire (RDQ)[34], which has 24 items, scored from 0 (no disability) to 24 (highest disability).

Anxiety and depression were measured by the Hospital Anxiety and Depression Scale (HADS) [49], scored from 0 (no distress) to 21 (high level of distress. Fear of pain, fear 
avoidance, catastrophising and coping were recorded differently in the two cohorts and were adapted into common scales when merging the data sets. Fear of pain and fear avoidance were recorded by the Tampa Scale of Kinesiophobia (TSK) [20] and catastrophising and coping by the Coping Strategies Questionnaire (CSQ24) [17] in the BeBack study. In the BaRNS study, single items were used to assess fear of pain, fear avoidance, catastrophising and coping. The items for fear of pain ("My body is telling me I have something dangerously wrong") and fear avoidance ("I can't do all the things normal people do because it's too easy for me to get injured") were originally taken from the TSK [20], and administered with a dichotomised response category (yes/no). Similarly, the catastrophising item ("The pain is terrible and I feel it's never going to get any better") and the coping item ("I tell myself I can't let the pain stand in the way of what I have to do") were taken from the CSQ24 [17], also administered with a dichotomised response category (yes/no). When merging the data sets in the current study, the same single items in the BeBack data set were dichotomised as follows: the original 4-point response categories (strongly disagree, disagree, agree, strongly agree) for the fear of pain item and fear avoidance item were dichotomised into "no" (strongly disagree and disagree) and "yes" (agree and strongly agree). Similarly, responses to the catastrophising and coping items were dichotomised into "no" (scores 0-1: "never".) and "yes" (scores 2-6: "sometimes / always".).

\subsection{Outcome measure}

We defined self-reported disability due to LBP, measured by the RDQ, as our outcome of interest, based on absolute scores of the RDQ at 12-month follow-up, with adjustment for baseline RDQ scores.

\subsection{Statistical analysis}

The potential prognostic indicators were grouped into demographic, physical, psychological and social domains according to the biopsychosocial model, and are presented separately for acute/subacute and chronic LBP subgroups using simple descriptive statistics. Descriptive statistics were also obtained for the main outcome (RDQ score) at baseline and 12 months follow-up, together with change in RDQ scores between the two time points. A correlation matrix (Pearson.s correlation coefficient) was estimated to describe correlations among the prognostic variables. Potential prognostic variables were included in univariable and multivariable regression analyses, adjusted for RDQ baseline scores, age, gender, and sample. The relationships between the potential prognostic indicators and outcome were analysed separately within each of the two LBP subgroups (acute/subacute and chronic). Univariable and multivariable regression models ascertained the independent relationships with RDQ outcome for the prognostic variables. The results are presented with unstandardised regression coefficients ( $(B)$ and their $95 \%$ confidence interval $(\mathrm{CI})$ and the $\% \mathrm{R}^{2}$ for each of the univariable analyses. -up, together with change in RDQ scores between the two time points. A correlation matrix (Pearson.s correlation coefficient) was estimated to describe correlations among the prognostic variables. Potential prognostic variables were included in univariable and multivariable regression analyses, adjusted for RDQ baseline scores, age, gender, and sample. The relationships between the potential prognostic indicators and outcome were analysed separately within each of the two LBP subgroups (acute/subacute and chronic). Univariable and multivariable regression models ascertained the independent relationships with RDQ outcome for the prognostic variables. The results are presented with unstandardised regression coefficients $(B)$ and their $95 \%$ confidence interval $(\mathrm{CI})$ and the $\% \mathrm{R}^{2}$ for each of the univariable analyses.

The correlation matrix together with regression analyses formed the basis for developing a final multivariable model. Variables that were associated with the outcome in the univariable analyses with a p-value of less than 0.10 were added into this analysis. Variables 
within the same domain were checked for redundancy by looking at the correlation coefficients and their standardised Betas in the presence of other variables in the same domain. Variables that were not significantly associated with the outcome were removed from the final model except for age, gender, study sample and RDQ baseline scores. For variables that were significantly associated with outcome, we tested for 2-way statistical interaction. Additionally, potential confounding was examined by changes in effect estimates. The residuals were examined to check model assumptions. Statistical Package for Social Science (SPSS) (version 16.0) was used and all p-values are two-sided. We used a $5 \%$ level of statistical significance.

Sensitivity analyses were carried out on patients with LBP episode duration of 3 years and more in the chronic LBP group $(\mathrm{n}=301)$. This group was chosen since previous research has shown that those with pain duration of 3 years or more at the time of consultation are more likely to have higher levels of pain and disability over a year of follow-up [11]. A sensitivity analysis of those with acute LBP less than 1 month was not possible as there were too few cases in this subgroup ( $\mathrm{n}=78$ at 12 months follow-up).

\section{Results}

\subsection{Study sample}

At baseline there were 2526 participants; 935 from the BaRNS and 1591 from the BeBack cohorts. Of the 2526 participants, 2065 (81.7\%) gave permission for further contact. The mean age of baseline responders was slightly higher in the BaRNS than in the BeBack cohort; 45.6 years (SD 8.45) versus 43.9 (SD 10.3) ( $\mathrm{p}=0.014)$. There were no statistical significant differences between the two data sets in distribution of gender, work satisfaction, widespreadness of pain, bothersomeness, Chronic Pain Grade, HADS anxiety and RDQ scores, either at baseline or at 12 months. The baseline responders in the two data sets differed with regard to some of the other variables. For example, in BaRNS there were significantly higher proportions $(<0.001)$ of lower class, unemployed, people with catastrophising and poor coping, and the BaRNS participants had significantly higher mean scores in pain intensity and HADS depression. On the other hand, in the BeBack cohort there were significantly (<.001) higher proportions of participants with distal leg pain, fear of pain and fear avoidance. There was also a significantly higher proportion of participants with acute/subacute LBP in the BeBack (38.8\%) as compared to the BaRNS cohort (21.7\%).

A total of 939 participants responded to the 12 months follow-up (45.5\% of consenters). There were no differences in baseline characteristics between responders and nonresponders to the 12 month questionnaire in terms of gender, work status, work absence due to LBP, pain sites or pain intensity, bothersomeness, Chronic Pain Grade, disability, or the psychological variables. The significant differences $(p<0.01)$ were that non-responders were younger, had lower social class and lower level of education, had higher fear of pain, but lower coping difficulties.

\subsection{Baseline characteristics of responders}

The baseline characteristics for the 258 cases with acute/subacute LBP (28\%) and 668 cases with chronic LBP $(72 \%)$ are presented in Table 1 . The chronic LBP subgroup had a significantly higher proportion of non-employed and people with work absence due to LBP than the acute/subacute LBP. Furthermore, there were more employed people who were not satisfied with their work in the chronic LBP subgroup. The participants in the chronic LBP subgroup scored significantly poorer on all the physical variables and most of the psychological variables. The only exceptions were fear of pain and fear avoidance, which were similar in the two subgroups. Moreover, there were no differences between those in the 
acute/subacute and chronic LBP subgroups in terms of age, gender, level of education and social class.

\subsection{Outcome}

The mean scores of disability (RDQ scores) at baseline and 12 month follow-up were statistically significantly lower in the acute/subacute LBP subgroup as compared to the chronic LBP subgroup (Table 2). Disability improved in both groups at the 12 months follow-up. There was a significantly larger improvement in the acute/subacute sugroup as compared to the chronic subgroup. The frequency distribution of the RDQ scores in Table 2 shows that there were large individual differences in the two subgroups with regard to level of disability at baseline and follow-up: at baseline, nearly half of the acute/subacute subgroup (48\%) and a third of the chronic subgroup (32\%) had lower disability scores of less than 6 RDQ points, whereas $10 \%$ in the acute/subacute subgroup and $16 \%$ in the chronic subgroup, respectively, scored in the upper end of the scale (> 16 out of 24 points). At 12 months follow-up, 77\% in the acute/subacute subgroup and 52\% in the chronic subgroup scored in the lower end (<6 RDQ points), with 5\% and $13 \%$ in the upper end, respectively.

\subsection{Baseline correlations}

Most of the correlation coefficients between the prognostic variables were low $(<0.40)$, thus co-linearity should not be a problem. The highest correlations were found between baseline RDQ and HADS depression ( $\mathrm{r} 0.60$ in acute/subacute and 0.56 in chronic, respectively), between baseline RDQ and work absence due to LBP in acute/subacute LBP (r 0.56), and between baseline RDQ and bothersomeness in chronic LBP (r 0.55). In both LBP subgroups there were high correlations between the two HADS subscales ( $\mathrm{r} 0.70$ and 0.62 , respectively) and between the two leg pain questions (r 0.66 and 0.67 , respectively). However correlations between the other psychological variables and between work status and work absence due to LBP were low in both LBP subgroups $(r<0.30)$.

The variables that were highly correlated were entered one at a time in the multivariable analyses. Since bothersomeness became negatively associated with the outcome in the adjusted analyses, it was not included in the final regression analyses (see 3.4).

\subsection{Prognostic indicators}

The unadjusted and adjusted associations between baseline prognostic indicators and RDQ at 12 months are presented in Table 3. All the physical variables and most of the social and psychological variables were associated with 12 months RDQ scores in the univariable analyses, whereas demographic factors and coping were not.

Adjusting for baseline RDQ had a strong impact on several of the associations. Among the social variables, level of education and work absence due to LBP in acute/subacute LBP, and work satisfaction in chronic LBP, became non-significantly associated with outcome. Among the physical variables, the leg pain variables became non-significant in both LBP subgroups, and the same happened to bothersomeness in acute/subacute LBP.

Bothersomeness became inversely related to RDQ at 12 months when adjusting for baseline RDQ. All the psychological variables, except HADS anxiety and fear avoidance in chronic LBP, remained significantly associated with outcome after adjusting for baseline RDQ.

Baseline RDQ explained much more of the variance in 12 month RDQ scores than any of the other variables; $32 \%$ in the acute/subacute LBP subgroup and $44 \%$ in the chronic LBP subgroup, respectively (Table 3 ). The proportion of variance explained by the other potential prognostic indicators was much lower, with work status the highest in both LBP subgroups 
(3.3\% and $4.2 \%$ ), followed by widespreadness of pain (1.9\% and 2.5\%), Chronic Pain Grade ( $2.5 \%$ and $1.8 \%)$, and catastrophising (2\% in both LBP subgroups).

The final multivariable regression models showed that a similar set of prognostic indicators (being non-employed, widespreadness of pain, high level of Chronic Pain Grade, and catastrophising) were significantly associated with disability at 12 months in both LBP subgroups (Table 4). The only difference was that fear of pain was significantly associated with disability in chronic LBP, but not in acute/subacute LBP. The model accounted for $37.5 \%$ of the total variance in acute/subacute LBP and $53.3 \%$ in chronic LBP, respectively.

In acute/subacute LBP a significant interaction was found between work status and catastrophising $(\mathrm{p}<0.001)$ and between work status and Chronic Pain Grade $(\mathrm{p}<0.001)$. The effect of high catastrophising at baseline was only significant among the non-employed, whereas high Chronic Pain Grade at baseline was only significant among the employed with acute/subacute LBP. There were no significant interactions between work status and widespread pain $(p=0.107)$ or any of the other independent variables $(p>0.107)$.

Also in the chronic LBP subgroup we found a significant interaction between work status and Chronic Pain Grade ( $\mathrm{p}=0.009$ ). The effect of high Chronic Pain Grade at baseline was only significant among employed patients with chronic LBP, and not among the nonemployed.

As a test of the validity of the results of the final models, we also carried out a backward regression analysis in which all variables that were initially significantly associated with the outcome with a p-value of less than 0.10 were included in the multivariable model without considering the different domains of the biopsychosocial model. The results were identical to those presented above.

\subsection{Sensitivity analyses}

The sensitivity analysis on patients reporting an episode duration of 3 years or more $(n=301)$, adjusting for age, gender, sample, and baseline RDQ, showed that a similar set of prognostic indicators (social class, work status, work absence due to LBP, widespreadness of pain, bothersomeness, Chronic Pain Grade, HADS anxiety, HADS depression and catastrophising) were significantly associated with disability at 12 months.

Since the impact of baseline RDQ scores on the outcome was so large in this study, and given that the baseline RDQ scores were fairly low for significant proportions of the acute and chronic pain patients (Table 2), we also carried out an additional analysis, excluding those with baseline scores of 9 or lower. Due to sample size, we carried out this analysis on the whole sample of cases with acute/subacute and chronic LBP; a total of 381 cases had RDQ baseline scores of 10 or higher ( 73 cases in the acute/subacute group and 308 cases in the chronic LBP group). Mean score at baseline was 15.04 (SD 3.67), at 12 months 10.55 (SD 6.91), and the mean change score was 4.48 (6.14). A similar set of prognostic indicators were significantly associated with disability at 12 months in the adjusted analyses (age, gender, sample, baseline RDQ) as compared to the findings in the whole data set, with the variables education, work status, widespreadness of pain, pain intensity, leg pain, leg pain below knee, CPG, and catastrophising being significantly associated with outcome. The only difference was that bothersomeness and the HADS scales were not associated with disability in the subgroup with higher baseline RDQ scores. The final multivariate model in this subgroup was similar to the previous final model in chronic LBP, showing that work status, widespreadness of upper body pain, high level of CPG, fear of pain, and catastrophising were significantly associated with disability at 12 months. 


\section{Discussion}

\subsection{Summary of main findings}

Despite significant differences between acute/subacute and chronic LBP patients seeking primary care, the same prognostic indicators influenced 12 months disability. The strength of the associations was surprisingly similar across the two LBP subgroups. Being nonemployed, having widespread pain, a high level of Chronic Pain Grade and catastrophising symptoms increased the risk of high disability at 12 months in both subgroups of LBP.

Furthermore, the baseline level of disability explained the largest proportion of variance in 12 months outcome: $32 \%$ in acute/subacute and $44 \%$ in chronic LBP. Each of the other significant prognostic indicators only explained between 2 to $4 \%$ of the variance in outcome. Overall, only a limited amount of variance was explained by the models. Hence, it is likely that other, as yet unmeasured prognostic indicators may well be important.

\subsection{Strengths and limitations of the study}

The main strength of this study is the large sample, containing a wide range of baseline data on physical, psychological and social variables from LBP patients consulting in primary care. We consider the two merged samples to be representative for the back pain population in the Staffordshire and Cheshire area of UK. The large sample size provided good statistical power to test the influence of different prognostic indicators on disability over time across the two subgroups of the LBP population.

We distinguished between short and long-term duration of present episode using a suggested cut-off of 3 months according to the classification proposed by de Vet et al [8]. Previous research has suggested that patients with pain duration of 3 years or more are more likely to have higher levels of pain and disability over a year of follow-up -up [11]. Our sensitivity analysis for this particular subgroup showed that the prognostic indicators for disability at 12 months follow-up were similar to the rest of the sample, and thus strengthens the findings of the main analysis.

A limitation of this study is the response rate, as only $45.5 \%$ of the baseline sample responded to the 12 months follow-up. Younger participants and those with lower social class, lower level of education, higher fear of pain and lower coping difficulties were less likely to respond to the survey. However, the responders and non-responders were similar with regard to other baseline variables. The low response rate might have affected the prevalence estimates, but importantly for the purpose of this paper it is unlikely that this has substantially influenced the comparisons between the two LBP subgroups. Furthermore, the baseline questionnaire reached patients between 1 to 2 weeks after their GP consultation and thus we may have missed those patients who recovered in the first couple of weeks and who did not respond to the baseline questionnaire.

Another potential limitation is that the two merged data sets were collected four years apart. For example, some prognostic indicators such as illness perceptions, were included in the second, but not in the first cohort, and hence could not be merged and tested in this study.

It can also be questioned whether dichotomised measurements used for the single items for fear of pain, fear avoidance and catastrophising, may have diluted potential associations with RDQ outcome. On the other hand, anxiety and depression were assessed by full scale measures (the HADS), and none of these remained significant in the final models, whereas the dichotomised variables of fear of pain and catastrophising both turned out to be stronger predictors than the full scale measured variables of HADS. 


\subsection{Comparison with existing literature}

Our main finding showing that a similar set of prognostic indicators is associated with longterm disability in both LBP groups is in line with the few other studies that have explored this topic. The large Australian inception cohort study found that several of the prognostic indicators in people with acute LBP $(<2$ weeks) [18] and for those who developed chronic LBP (>3 months)[4] overlap, for example high disability or pain intensity at baseline and greater perceived risk of persistent pain were associated with a longer time to recovery in both groups. Furthermore, emotional distress had a similar impact on disability at 12 months in two largely different LBP subgroups; first-time consulters in primary care with acute LBP ( $<3$ weeks) and secondary care consulters with chronic LBP ( $>1$ year) [16]. Our results are also similar to a systematic review [27], which found that pain characteristics at the time of consultation, levels of disability and psychological factors, were all associated with subsequent outcome in multiple studies investigating different pain sites. An earlier systematic review [32] concluded that the role of fear of pain in the development of chronic LBP is overrated and that depression/distress was more important. The present study shows that fear of pain and catastrophising are significant indicators of outcome in primary care whereas depression was not. However other recent empirical studies suggest, as does the present study, that components of cognitive distress such as fear of pain or catastrophising do predict the development or continuation of pain [23;31]. Not all potentially important psychological constructs were included in the present study. For example, in a recent published analysis [13;32], the influence of 20 potential psychological predictors on disability at 6-months follow-up were compared, and illness perceptions rather than catastrophising, fear of pain or depression were found to be the strongest predictors of outcome. It is clear that more studies in this field are needed to identify which psychological construct(s) are most important for future disability in patients with LBP and most useful with respect to designing potential interventions.

Although the psychological factors were significantly associated with outcome in the current study, the size of the associations was fairly low. This finding is in line with the above mentioned study [16], which showed that despite both emotional distress and many pain and disability variables being significantly associated with the Oswestry Disability Index, emotional distress explained only 5-8\% of the variance, whereas the pain and disability variables explained $28-44 \%$. In the other comparable studies the size of the associations in terms of explained power was not reported [18]. In contrast to both the psychological and other factors in the present study, the impact of the both the psychological and other factors in the present study, the impact of the baseline scores of the RDQ was clearly the strongest in both groups. The large impact of baseline disability scores on outcome has been shown in many previous prognostic studies [2-6;21;35;36]. Moreover, the tendency among people to either score in the lower or the upper end of a scale has been confirmed in a study by Dunn et al [12]. They found that no one who scored in the lower part of the scale (e.g. pain less than 5 on a $0-10$ scale) developed high scores during a 6 month follow-up period. These findings call for a wider repertoire of primary care interventions and more careful assessment of their effectiveness for back-related pain and disability.

The strong association between being non-employed and long-term disability is similar to findings of another UK study, showing that non-employed people were more likely to have high levels of disability, anxiety and/or depression and report longer duration of LBP than those who were unemployed for reasons other than LBP [48]. Our findings suggest that prognostic indicators might be different in non-working populations as compared to working populations. Further prognostic studies specifically with non-employed people with LBP to match the many prognostic studies from occupational settings [15;25;30;43]. 


\subsection{Implications for future research and clinical practice}

This study suggests that there are a few prognostic indicators consistently associated with long-term disability regardless of duration of the LBP episode. The low number of prognostic indicators is encouraging from a clinical perspective, as a small set of indicators can be more easily identified and addressed in clinical practice. Short episode duration is itself a good prognostic factor relative to longer duration, but these results provide further evidence that similar prognostic indicators are present throughout the duration of a LBP episode and increasing duration selectively identifies a group more likely to have continuing disability. Clinical guidelines recommend that health professionals consider and screen for psychosocial factors, but first after 6 weeks of pain duration [1;44]. Our findings, along with other findings in samples with acute LBP $[2 ; 5 ; 6 ; 21 ; 36]$ suggest that early screening and targeted treatment should be considered regardless of pain duration. Further research is needed regarding both acceptable screening approaches and optimal targeted interventions for those who are at risk of poor outcome.

\section{Conclusion}

A similar set of prognostic indicators is associated with long-term disability in both acute/ subacute and chronic LBP subgroups in primary care. Baseline level of disability, being not employed, having widespread pain, a high level of Chronic Pain Grade, and catastrophising were the strongest prognostic indicators in both LBP subgroups. Fear of pain was a prognostic indicator of long-term disability in chronic LBP. Importantly, beyond baseline disability, the effect size of the other prognostic indicators for poor outcome was rather low. These findings must continue to challenge researchers to identify useful early predictors of outcome in persons with disabling back pain, as screening and targeted treatment approaches are dependent upon prognostic indicators with clinical significance.

\section{Acknowledgments}

Funding for the two cohort studies: Wellcome Trust (BaRNS), Arthritis Research, UK (BeBack). The research teams, GP practices and patients that supported each of the two cohort studies. NEF was funded through a Primary Care Career Scientist award from the National Institute of Health Research, UK. KMD is funded by a Research Career Development Fellowship from the Wellcome Trust.

Thanks also to Dr. Kelvin Jordan for his useful comments regarding the statistical analyses.

\section{References}

[1]. Airaksinen O, Brox JI, Cedraschi C, Hildebrandt J, Klaber-Moffett J, Kovacs F, Mannion AF, Reis S, Staal JB, Ursin H, Zanoli G. European guidelines for the management of chronic nonspecific low back pain. Eur Spine J. 2006; 15(Suppl 2):S192-S300. [PubMed: 16550448]

[2]. Burton AK, Tillotson KM, Main CJ, Hollis S. Psychosocial predictors of outcome in acute and subchronic low back trouble. Spine. 1995; 20:722-728. [PubMed: 7604349]

[3]. Carey TS, Garrett JM, Jackman AM. Beyond the good prognosis: Examination of an inception cohort of patients with chronic low back pain. Spine. 2000; 25(1):115-120. [PubMed: 10647169]

[4]. Costa LC, Maher CG, McAuley JH, Hancock MJ, Herbert RD, Refshauge KM, Henschke N. Prognosis for patients with chronic low back pain: inception cohort study. BMJ. 2009; 339:b3829. [PubMed: 19808766]

[5]. Coste J, Delecoeuillerie G, Cohen de Lara A, Parc J, Paolaggi J. Clinical course and prognostic factors in acute low back pain: an inception cohort study in primary care practice. BMJ. 1994; 308:577-580. [PubMed: 8148683]

[6]. Coste J, Lefrancois G, Guillemin F, Pouchot J. Prognosis and Quality of Life in Patients With Acute Low Back Pain: Insights From a Comprehensive Inception Cohort Study. Arthritis Rheum. 2004; 51(2):168-176. [PubMed: 15077256] 
[7]. Crook J, Moldofsky H, Shannon H. Determinants of Disability After a Work Related Musculoskeletal Injury. J Rheumatol. 1998; 25:1570-1577. [PubMed: 9712103]

[8]. de Vet HC, Heymans MW, Dunn KM, Pope DP, Van der Beek AJ, Macfarlane GJ, Bouter LM, Croft PR. Episodes of low back pain: a proposal for uniform definitions to be used in research. Spine. 2002; 27(21):2409-2416. [PubMed: 12438991]

[9]. Deyo RA, Battie M, Beurskens AJ, Bombardier C, Croft P, Koes B, Malmivaara A, Roland M, Von Korff M, Waddell G. Outcome measures for low back pain research. A proposal for standardized use. Spine. 1998; 23(18):2003-2013. [PubMed: 9779535]

[10]. Dunn KM, Croft PR. Classification of low back pain in primary care: using "bothersomeness" to identify the most severe cases. Spine. 2005; 30(16):1887-1892. [PubMed: 16103861]

[11]. Dunn KM, Croft PR. The importance of symptom duration in determining prognosis. Pain. 2006; 121(1-2):126-132. [PubMed: 16472916]

[12]. Dunn KM, Jordan K, Croft PR. Characterizing the course of low back pain: a latent class analysis. Am J Epidemiol. 2006; 163(8):754-761. [PubMed: 16495468]

[13]. Foster NE, Thomas E, Bishop A, Dunn KM, Main CJ. Distinctiveness of psychological obstacles to recovery in low back pain patients in primary care. Pain. 2010; 148(3):398-406. [PubMed: 20022697]

[14]. Foster NE, Bishop A, Thomas E, Main C, Horne R, Weinman J, Hay E. Illness perceptions of low back pain patients in primary care: what are they, do they change and are they associated with outcome? Pain. 2008; 136(1-2):177-187. [PubMed: 18313853]

[15]. Fransen M, Woodward M, Norton R, Coggan C, Dawe M, Sheridan N. Risk factors associated with the transition from acute to chronic occupational back pain. Spine. 2002; 27(1):92-98. [PubMed: 11805644]

[16]. Grotle M, Vollestad NK, Brox JI. Clinical course and impact of fear-avoidance beliefs in low back pain: prospective cohort study of acute and chronic low back pain: II. Spine. 2006; 31(9): 1038-1046. [PubMed: 16641782]

[17]. Harland NJ, Georgieff K. Development of the coping strategies questionnaire 24, a clinically utilitarian version of the coping strategies questionnaire. Rehab Psychology. 2003; 48(4):296300 .

[18]. Henschke N, Maher C, Refshauge K, Herbert RD, Cumming RG, Bleasel J, York J, Das A, McAuley JH. Prognosis in patients with recent onset low back pain in Australian primary care: inception cohort study. BMJ. 2008; 337:171. doi:10.1136/bmj.al71.

[19]. Kent PM, Keating JL. Can we predict poor recovery from recent-onset non-specific low back pain? A systematic review. Manual Ther. 2007 doi:10.1016/j.math.2007.05.009.

[20]. Kori SH, Miller RP, Todd DD. Kinesiophobia: a new view of chronic pain behaviour. Pain Manag. 1990; 3:35-43.

[21]. Kovacs FMM. The Transition from Acute to Subacute and Chronic Low Back Pain: A Study Based on Determinants of Quality of Life and Prediction of Chronic Disability. Spine. 2005; 30(15):1786-1792. [PubMed: 16094282]

[22]. Kuch K. Psychological factors and the development of chronic pain. Clin J Pain. 2001; 17(4 Suppl):S33-S38. [PubMed: 11783829]

[23]. Leeuw M, Houben RM, Severeijns R, Picavet HS, Schouten EG, Vlaeyen JW. Pain-related fear in low back pain: a prospective study in the general population. Eur J Pain. 2007; 11(3):256-266. [PubMed: 16546425]

[24]. Linton SJ. Occupational psychological factors increase the risk for back pain: a systematic review. J Occupational Rehab. 2001; 11(1):53-66.

[25]. Loisel P, Gosselin L, Durand P, Lemaire J, Poitras S, Abenhaim L. Implementation of a participatory ergonomics program in the rehabilitation of workers suffering from subacute back pain. Appl Ergonom. 2001; 32(1):53-60.

[26]. Macfarlane GJ, Thomas E, Croft PR, Papageorgiou AC, Jayson MI, Silman AJ. Predictors of early improvement in low back pain amongst consulters to general practice: the influence of premorbid and episode-related factors. Pain. 1999; 80(1-2):113-119. [PubMed: 10204723] 
[27]. Mallen CD, Peat G, Thomas E, Dunn KM, Croft PR. Prognostic factors for musculoskeletal pain in primary care: a systematic review. Br J Gen Pract. 2007; 57(541):655-661. [PubMed: 17688762]

[28]. McIntosh G, Frank J, Hogg-Johnson S, Hall H, Bombardier C. Low back pain prognosis: Structured review of the literature. J Occupational Rehab. 2000; 10(2):101-115.

[29]. Office for National Statistics. Standard occupational classification. The coding index, vol. 2. The Stationary Office; London: 2000. Version 1.1. 2002. London, Office for National Statistics. The National Statistics Socio-economic classification user manual

[30]. Ohlund C, Eek C, Palmbald S, Areskoug B, Nachemson A. Quantified pain drawing in subacute low back pain. Validation in a nonselected outpatient industrial sample. Spine. 1996; 21(9): 1021-1030. [PubMed: 8724085]

[31]. Picavet HSJ, Vlaeyen JWS, Schouten JSAG. Pain catastrophizing and kinesiophobia: Predictors of chronic low back pain. Am J Epidemiol. 2002; 156(11):1028-1034. [PubMed: 12446259]

[32]. Pincus T, Vogel S, Burton AK, Santos R, Field AP. Fear avoidance and prognosis in back pain: a systematic review and synthesis of current evidence. Arthritis Rheum. 2006; 54(12):3999-4010. [PubMed: 17133530]

[33]. Rohling ML, Binder LM, Langhinrichsen Rohling J. Money matters: a meta-analytic review of the association between financial compensation and the experience and treatment of chronic pain. Health Psychol. 1995; 14(6):537-547. [PubMed: 8565928]

[34]. Roland M, Morris R. A Study of the Natural History of Back Pain. Part I: Development of a Reliable and Sensitive Measure of disability in low back pain. Spine. 1983; 8(2):141-144. [PubMed: 6222486]

[35]. Roland M, Morris R. A study of the natural history of low-back pain: Part II: Development of guidelines for trials of treatment in primary care. Spine. 1983; 8:145-150. [PubMed: 6222487]

[36]. Schiottz-Christensen B, Nielsen GL, Hansen VK, Schodt T, Sorensen HT, Olesen F. Long-term prognosis of acute low back pain in patients seen in general practice: A 1-year prospective follow-up study. Fam Pract. 1999; 16(3):223-232. [PubMed: 10439974]

[37]. Steenstra IA, Koopman FS, Knol DL, Kat E, Bongers PM, de Vet HC, van Mechelen W. Prognostic factors for duration of sick leave due to low back pain in Dutch health care professionals. J Occup Rehabil. 2005; 15(4):591-605. [PubMed: 16254758]

[38]. Teasell RW. Compensation and chronic pain. Clin J Pain. 2001; 14(4 Suppl):S46-S51. [PubMed: 11783831]

[39]. Teasell RW, Bombardier C. Employment-related factors in chronic pain and chronic pain disability. Clin J Pain. 2001; 17(4 Suppl):S39-S45. [PubMed: 11783830]

[40]. Thomas E, Silman AJ, Croft PR, Papageorgiou AC, Jayson MIV, Macfarlane GJ. Predicting who develops chronic low back pain in primary care: a prospective study. BMJ. 1999; 318(24):16621667. [PubMed: 10373170]

[41]. Truchon M, Fillion L. Biopsychosocial determinants of chronic disability and low-back pain: A review. J Occup Rehabil. 2000; 10(2):117-142.

[42]. van den Hoogen HJM, Koes BW, Devillé W, van Eijk JTM, Bouter LM. The Prognosis of Low Back Pain in General Practice. Spine. 1997; 22(13):1515-1521. [PubMed: 9231972]

[43]. van der Weide WE, Verbeek JHA, Salle HJA, Van Dijk FJH. Prognostic factors for chronic disability from acute low-back pain in occupational health care. Scand J Work, Environ \& Health. 1999; 25(1):50-56. [PubMed: 10204671]

[44]. van Tulder M, Becker A, Bekkering T, Breen A, del Real MT, Hutchinson A, Koes B, Laerum E, Malmivaara A. COST B13 Working Group on Guidelines for the Management of Acute Low Back Pain in Primary Care: European guidelines for the management of acute nonspecific low back pain in primary care. Eur Spine J. 2006; 15((Suppl2):S169-S191. [PubMed: 16550447]

[45]. Von Korff M, Deyo RA, Cherkin DC, Barlow W. Back Pain In Primary Care: Outcomes At 1 Year. Spine. 1993; 18(7):855-862. [PubMed: 8316884]

[46]. Von Korff M, Ormel J, Keefe FJ, Dworkin SF. Grading the severity of chronic pain. Pain. 1992; 50:133-149. [PubMed: 1408309]

[47]. von KM, Dunn KM. Chronic pain reconsidered. Pain. 2008; 138(2):267-276. [PubMed: 18226858] 
[48]. Wynne-Jones G, Dunn KM, Main CJ. The impact of low back pain on work: a study in primary care consulters. Eur J Pain. 2008; 12(2):180-188. [PubMed: 17561421]

[49]. Zigmond AS, Snaith RP. Hospital Anxiety and Depression Scale (HAD). Acta Psychiatr Scand. 1983; 67:361-370. [PubMed: 6880820] 


\section{Summary}

Despite significant differences between subgroups of acute/subacute and chronic LBP, a similar set of prognostic indicators seem to influence long-term disability in both subgroups. 


\section{Table 1}

Baseline characteristics of participants with low back pain who responded to 12 months follow-up. Frequency and percent in parentheses for categories and mean (SD) for continuous variables.

\begin{tabular}{|c|c|c|c|}
\hline Characteristic & $\begin{array}{c}\text { Acute/subacute LBP } \\
\mathbf{N = 2 5 8}\end{array}$ & $\begin{array}{c}\text { Chronic LBP } \\
\mathrm{N}=668\end{array}$ & $\begin{array}{c}\text { p-value } \\
\text { (between groups) }\end{array}$ \\
\hline \multicolumn{4}{|l|}{ Demographic } \\
\hline Mean age (SD) & $46(9)$ & $46(9)$ & .995 \\
\hline Gender (female) & $150(58)$ & $396(59)$ & .751 \\
\hline Sample (BeBack) & $171(66)$ & $293(44)$ & $<.001$ \\
\hline \multicolumn{4}{|l|}{ Social } \\
\hline Education (<1G years) & $95(37)$ & $300(45)$ & .063 \\
\hline Social class (low) & $94(42)$ & $212(47)$ & .805 \\
\hline Work status (not employed) & $48(19)$ & $203(31)$ & $<.001$ \\
\hline Work satisfaction (low) (only employed) & $45(22)$ & $132(29)$ & .041 \\
\hline Work absence due to LBP & $38(15)$ & $148(23)$ & .007 \\
\hline \multicolumn{4}{|l|}{ Physical } \\
\hline Leg pain & $135(52)$ & $432(65)$ & $<.001$ \\
\hline Leg pain below knee & $77(30)$ & $265(40)$ & .005 \\
\hline \multicolumn{4}{|l|}{ Wide spreadness of pain } \\
\hline 0 : none & $112(44)$ & $194(29)$ & $<.001$ \\
\hline 1: one + LBP & $63(25)$ & $162(24)$ & \\
\hline 2: two + LBP & $50(19)$ & $146(22)$ & \\
\hline $3: \geq 3+\mathrm{LBP}$ & $31(12)$ & $162(24)$ & \\
\hline Pain intensity (high) & $75(30)$ & $295(45)$ & $<.001$ \\
\hline \multicolumn{4}{|l|}{ Bothersomeness } \\
\hline 1 :Not at all & 18(7) & 19(3) & .006 \\
\hline 2: Slightly & $36(14)$ & $80(12)$ & \\
\hline 3: Moderately & $82(32)$ & $191(29)$ & \\
\hline 4: Very much & $75(30)$ & $261(39)$ & \\
\hline 5: Extremely & $43(17)$ & $112(17)$ & \\
\hline CPG (high) & $49(19)$ & $192(29)$ & .003 \\
\hline \multicolumn{4}{|l|}{ Psychological } \\
\hline HADS -anxiety (0-21), mean (SD) & $7.54(4.54)$ & $8.73(4.58)$ & $<.001$ \\
\hline HADS-depression (0-21), mean (SD) & $5.44(4.25)$ & $7.13(4.32)$ & $<.001$ \\
\hline Fear of pain & $52(20)$ & $142(21)$ & .746 \\
\hline Fear avoidance & $52(20)$ & $176(26)$ & .057 \\
\hline Catastrophising & $36(14)$ & $162(24)$ & .001 \\
\hline Coping & $120(47)$ & $381(57)$ & .005 \\
\hline
\end{tabular}




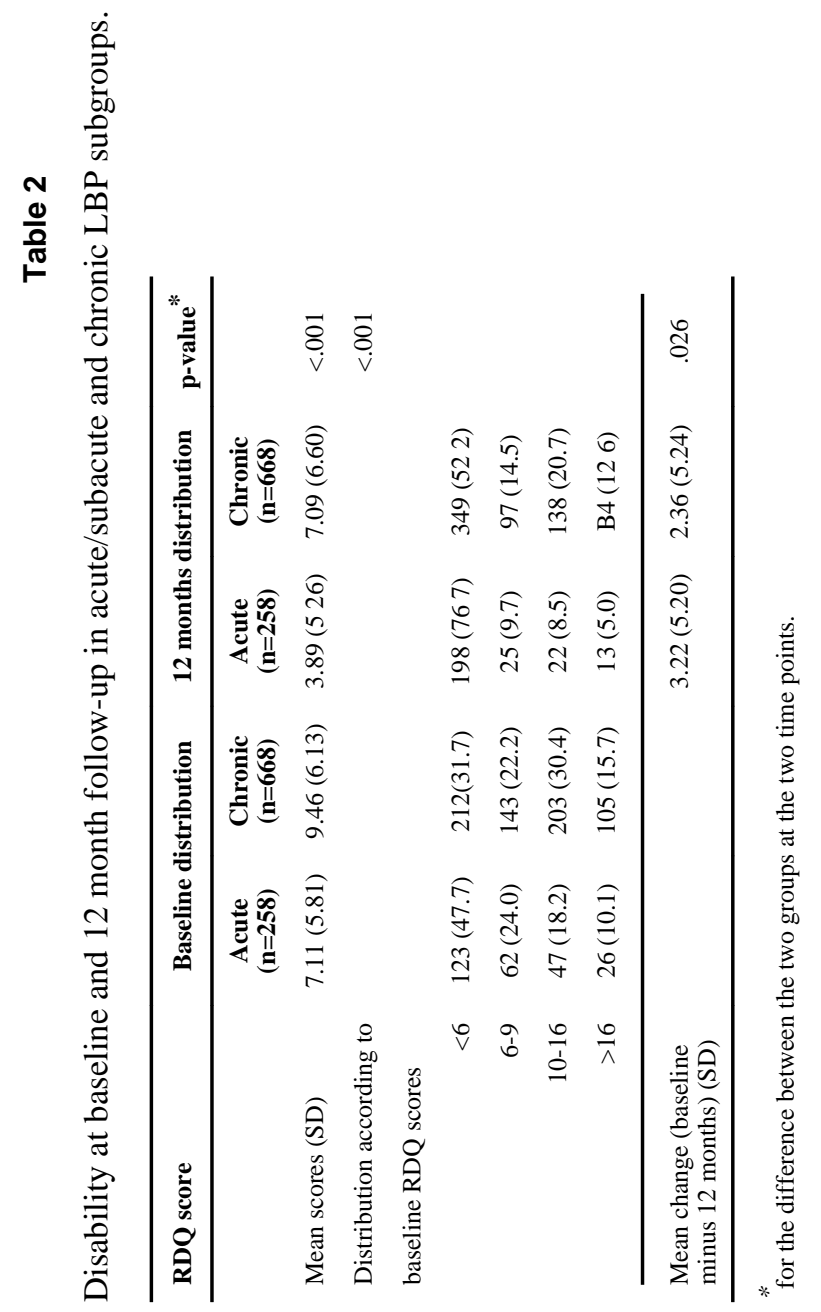

Pain. Author manuscript; available in PMC 2012 July 17. 


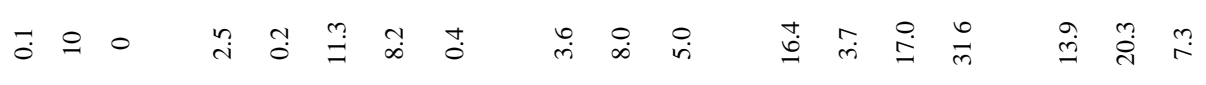

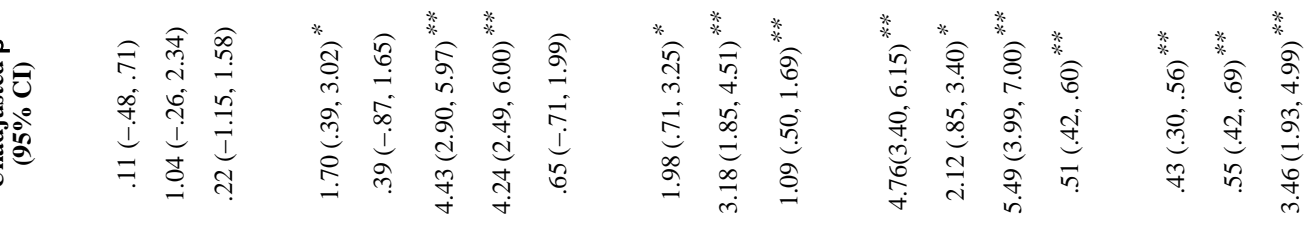

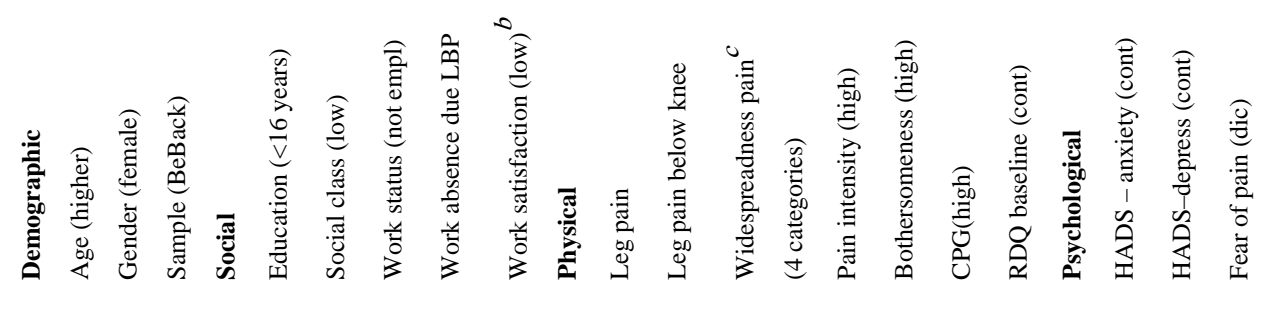




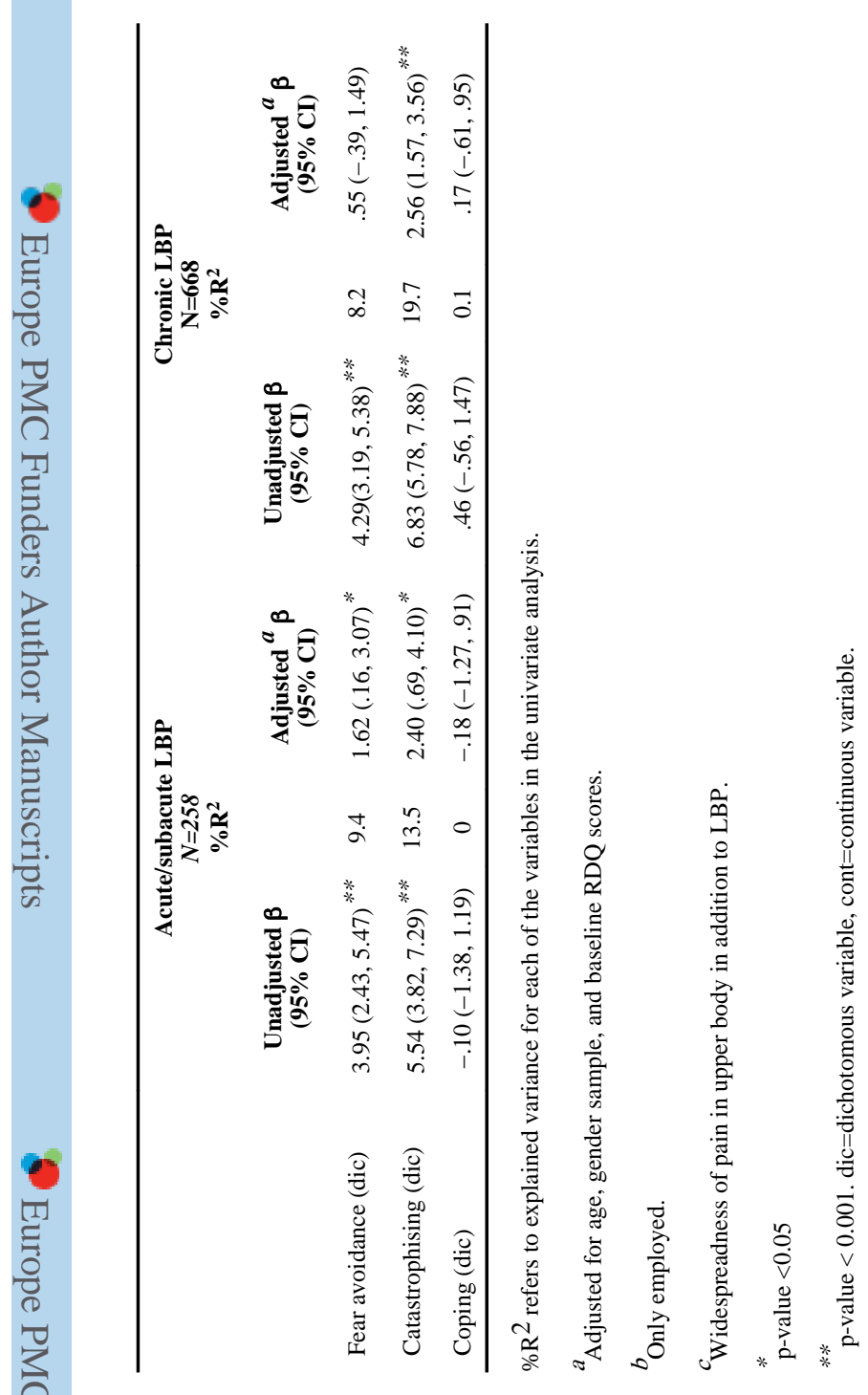

Pain. Author manuscript; available in PMC 2012 July 17. 


\section{Table 4}

Final models of prognostic indicators for RDQ absolute scores at 12 months follow-up in acute/subacute LBP and chronic LBP subgroups.

\begin{tabular}{rcccc}
\hline Acute/subacute LBP & $\boldsymbol{\beta}$ & $\mathbf{9 5 \%} \mathbf{C I}$ & $\begin{array}{c}\text { Standardised } \\
\text { Beta }\end{array}$ & p-value \\
Being not employed & 2.73 & $1.37,4.20$ & 0.21 & $<0.001$ \\
Widespread pain & 0.61 & $0.11,1.10$ & 012 & 0.017 \\
Chronic Pain Grade & 2.00 & $0.47,3.53$ & 0.15 & 0.010 \\
Catastrophising & 1.68 & $-001,3.36$ & 0.11 & 0.051 \\
Chronic LBP & & & & \\
Being not employed & 2.88 & $2.03,3.74$ & 0.20 & $<0.001$ \\
Widespread pain & 0.06 & $0.34,0.98$ & 0.12 & $<0.001$ \\
Chronic Pain Grade & 1.29 & $0.36,2.21$ & 0.09 & 0.006 \\
Fear of pain & 1.30 & $0.35,2.26$ & 0.08 & 0.008 \\
C atastrophising & 1.66 & $0.63,2.63$ & 0.11 & 0.001 \\
\hline
\end{tabular}

Analysis adjusted for age, gender, baseline RDQ and sample.

${ }^{1}$ R Square $37.5 \%$. adjusted R Square $35.7 \%$. The adjustment variables accounted for $30.7 \%$ of the outcome.

${ }^{2}$ R Square $53.3 \%$. adjusted R Square $52.7 \%$. The adjustment variables accounted for $45.2 \%$ of the outcome. 